\title{
A new mother-assisted rearing and release technique ("born to be free") reduces the exploratory movements and increases survival of young capercaillies
}

\author{
Dorota Merta • Janusz Kobielski • Andrzej Krzywiński • \\ Jörn Theuerkauf • Roman Gula
}

Received: 17 June 2014 / Revised: 27 December 2014 / Accepted: 1 January 2015 /Published online: 24 January 2015

(C) The Author(s) 2015. This article is published with open access at Springerlink.com

\begin{abstract}
We compared the mobility and survival rates of two groups of young capercaillies that were reared and released by different methods. One group consisted of 21 radio-tracked chicks that were incubated, reared in semi-liberty by their captive mother and released next to the cage of their mother (mother-assisted group). Another 30 radio-tracked chicks were reared in captivity and released in the absence of their mother (control group). The released young of the motherassisted group gravitated around their mother's cage, moved less and had smaller ranges than those of the control group. The mother-assisted males survived on average $549 \pm 331$
\end{abstract}

Communicated by H. Kierdorf

Electronic supplementary material The online version of this article (doi:10.1007/s10344-015-0899-3) contains supplementary material, which is available to authorized users.

\section{Merta $(\bowtie)$}

Department of Ecology, Wildlife Research and Ecotourism

Pedagogical University of Cracow, Podbrzezie 3

31-054 Cracow, Poland

e-mail: dorota-zbl@o2.pl

\section{J. Kobielski}

Ruszów Forest Inspectorate, Leśna 2, 59-950 Ruszów, Poland

e-mail: janusz.kobielski@wroclaw.lasy.gov.pl

\author{
A. Krzywiński \\ Wildlife Park Kadzidłowo, Kadzidłowo 2, 12-220 Ruciane \\ Nida, Poland \\ e-mail: park@kadzidlowo.pl \\ J. Theuerkauf $\cdot$ R. Gula \\ Museum and Institute of Zoology, Polish Academy of Sciences \\ Wilcza 64, 00-679 Warsaw, Poland \\ J. Theuerkauf \\ e-mail: jtheuer@miiz.eu \\ R. Gula \\ e-mail: rgula@miiz.eu
}

(confidence interval) days while males of the control group survived $253 \pm 134$ days. Corresponding survival for females was $293 \pm 164$ and $56 \pm 29$ days. We believe that motherassisted rearing and release reduces the mortality of capercaillie chicks because they are assisted by anti-predator behaviour of their mother and explore the new environment in a similar way as chicks hatched in the wild.

Keywords Reintroduction $\cdot$ Mother-assisted rearing $\cdot$ Chick survival $\cdot$ Breeding and releasing method $\cdot$ Tetrao urogallus

\section{Introduction}

To restock or re-establish local populations of capercaillies, the release of birds reared in captivity or caught in the wild has become a common tool (Storch 2007). However, most of the released birds usually die during the first weeks after release, mainly due to predation (e.g. Schroth 1991; Siano et al. 2006). We assumed that breeding and release conditions determine whether chicks possess certain foraging skills and anti-predator behaviour. Therefore, birds lacking these skills might have a reduced chance for survival in nature. To test this hypothesis, we compared mobility and survival rates of two groups of young capercaillies that were reared and released by different methods.

\section{Study area and methods}

The study area is located in the western part of the Lower Silesia Forest, a continuous lowland (140-180 m a.s.l.) forest area covering $2500 \mathrm{~km}^{2}$. The average annual temperature is 
$8.3^{\circ} \mathrm{C}$ and average annual precipitation $550 \mathrm{~mm}$, and there are approximately 40 days with snow cover. The forest is dominated by Scots pine (Pinus sylvestris) constituting $93 \%$ of forest stands, with undergrowth consisting of berries such as Vaccinium spp. A 2006 census of capercaillies in the study area counted 18 birds and another in 2009 recorded only two birds (Merta et al. 2013). Due to these critically low numbers and limited potential for natural recolonisation, the Ruszów Forest Inspectorate decided in 2009 to start a restocking programme using captive-reared birds.

In 2010-2013, we released a total of 98 young capercaillies (54 males and 44 females), of which 51 were fitted with radio transmitters (Biotrack Ltd backpack transmitters with mortality sensors, weighing $33 \mathrm{~g}$ corresponding to $1 \%$ of body mass of males and $1.8 \%$ of females) and colour leg bands. They originated from two breeding centres and hatched between May 15 and June 10.

One radio-tracked group (mother-assisted group) consisted of all 21 (13 males and 8 females) released chicks that were incubated and reared by their mothers in semi-natural conditions, according to the "born to be free" method (Krzywiński et al. 2013). Chicks of this group were offspring of females from Belarus and males from the Polish lowlands. They were from two broods in 2010 and 2011 and from one brood in 2012 and 2013. Their mothers were kept in an aviary of ca. $20 \mathrm{~m}^{2}$, which was situated in a clearing within a large forest complex. The females incubated and reared chicks on their own while the chicks could, from the first day after hatching, move freely out of the aviary through an opening that was too small for the mother to pass and find natural food on their own in the surrounding. The birds were provided with additional food of natural origin (insects and berries). In late August, at the age of 13 weeks, they were transported together with their mother $700 \mathrm{~km}$ to the release area in Lower Silesia and placed in an acclimatisation cage. The acclimatisation cage consisted of two adjacent but separated cages for the mother and the young. After 4-5 days, the aviary of the young was opened and they began to explore the surrounding forest. In September, at the age of 16 weeks, we fitted young with radio transmitters. Young birds of the mother-assisted group were at this time still in aural and visual contact with their mother, as the hen was left in the enclosure until the young dispersed in late October/early November at the age of 19-21 weeks

The control group consisted of 30 radio-tracked chicks (14 males and 16 females) that were reared in a breeding centre that used standard breeding methods. Chicks of this group were of Belarusian parents and originated from one brood in 2010, two broods in 2011, two broods in 2012 and one brood in 2013. Eggs were incubated either by capercaillies, chickens (Gallus gallus domesticus) or artificial incubators. For a week after hatching, chicks were kept in nursery cages, and then they were adopted and nursed by capercaillie hens. All chicks were kept in a forested enclosure, with some natural food available, and they were fed with food of natural origin (berries and insects). At the age of 16 weeks, young were transported $300 \mathrm{~km}$ to the acclimatisation aviaries in Lower Silesia and fitted with radio transmitters. The aviaries were identical to those for young of the mother-assisted group and situated several hundred metres apart. All chicks of the control group were released in the absence of their mothers after 4-5 days of acclimatisation.

For both groups, the acclimatisation area $\left(0.18 \mathrm{~km}^{2}\right)$ was surrounded by fladry line (strips of brightly coloured textile on ropes), and the central area $\left(0.04 \mathrm{~km}^{2}\right)$ by electric fence and ultrasonic emitters to deter potential predators. We located all individuals by triangulation from a distance (so that birds could not detect our presence) 11-28 times per 15-day interval during the first 75 days after release. We calculated cumulative $100 \%$ minimum convex polygon (MCP) ranges of each released bird for the first 15, 30, 45, 60 and 75 days after release.

We compared the survival rates of the two groups with the Kaplan-Meier estimator (Kaplan and Meier 1958) and estimated the daily survival rates as the number of deaths divided by the total time birds were radio-tracked (Heisey and Fuller 1985). As released males survived longer than females (Table 1), we therefore controlled for sex when comparing the two rearing methods (this also controlled for the different sex ratios of the two groups). If a bird was found dead, we estimated the end of radio-tracking as the average time between the day we found the dead bird and the last day we found this bird alive. Accordingly, if we lost contact with a bird, we estimated the end of radio-tracking as the average time between the day we radio-located the bird for the last time and the first day we searched for the bird but could not find it anymore. The period of radio-tracking ended with either the death of the bird or the failure of the transmitter. If we observed a bird later, we did not add this time to the length of radio-tracking as it would have biased the results towards higher survival. In case we lost contact with a bird, we considered the bird to be alive at the end of radiotracking. We assessed the cause of death by examining residuals of the body, tracks and droppings left by predators at the kill site, or by necropsy and microbiological tests in case signs of predators were absent.

\section{Results}

During the first 15 days after release, all birds of the mother-assisted group stayed and foraged next to the aviary of their mother and usually perched at night in a nearby tree. After dispersal in late October/early November, we frequently observed groups of two to three males, while females usually stayed alone. During the rearing period, we observed that the mother gave a specific alarm call when she noticed raptors. In response to this call, young chicks hid motionless in the 
Table 1 Cumulative length of radio-tracking, average survival time (with $95 \%$ confidence interval), daily mortality rate and percentage of casualties (in brackets those due to predation) of 51 released young capercaillies

\begin{tabular}{|c|c|c|c|c|}
\hline Group & Radio-tracking length (days) & Survival time (days) & Daily mortality (\%) & Casualties (predation) \\
\hline Mother-assisted females $(n=8)$ & 1959 & $293 \pm 164$ & 0.26 & $63 \%(50 \%)$ \\
\hline Mother-assisted males $(n=13)$ & 4571 & $549 \pm 331$ & 0.15 & $54 \%(23 \%)$ \\
\hline Control group females $(n=16)$ & 736 & $56 \pm 29$ & 1.77 & $81 \%(63 \%)$ \\
\hline Control group males $(n=14)$ & 2309 & $253 \pm 134$ & 0.30 & $50 \%(36 \%)$ \\
\hline
\end{tabular}

vegetation until the mother produced another call. In contrast, young birds of the control group fled immediately after release, settling several hundred metres away, and did not come back to the release area. We did not observe social interactions among these birds. The mean MCP range of the control group was already during the first 15 days after release 5 times larger than that of the mother-assisted group (Fig. 1).

The mother-assisted birds survived longer than birds of the control group (log-rank Mantel-Cox test adjusted for sex: $p=$ 0.007). The mean survival time of females reared by their mothers was more than five times longer and the daily mortality rate nearly seven times lower than that of females of the control group (Table 1). Mother-assisted males survived more than twice as long as males of the control group (Table 1). Among mother-assisted birds that did not survive, 7 of 12 $(58 \%)$ birds were killed by predators ( 3 by goshawk, 2 by fox, 2 by pine marten), while 15 of 20 (75\%) deceased birds of the control group were killed by predators ( 9 by goshawk, 4 by fox, 2 by pine marten). Other causes of mortality were collisions with trees and fences (three), diseases (one of sepsis and one of aspergillosis) and electric shocks (two), and in three cases, we were unable to determine the cause (see "Electronic supplementary material" for details).

In 2013, we observed three broods of which two were of females from the mother-assisted group and one from the control group. In 2014, we observed at 4 leks, a total of 12 males and 7 females, of which 6 were of the mother-assisted group ( 2 females and 4 males), 1 male of the control group, and 1 offspring of 2 released birds (female of the control group, male of the mother-assisted group). Moreover, in 2014, we observed two broods by females of the mother-assisted group.

\section{Discussion}

Our results demonstrated that mother-assisted rearing and release increased the survival rate of chicks. In contrast, mortality of young that were reared without the mother was very high as also observed in other studies (e.g. Schroth 1991: $57 \%$ in the first 2 weeks after release; Siano et al. 2006: $79 \%$ in the first 4 weeks). We think that mother-assisted birds survive longer not only because they are less mobile but also because their mothers' warnings helped them to avoid predators. Mother- assisted chicks might therefore have learned effective antipredator behaviour quicker than chicks of the control group. Predation risk in the control group might have been higher first because a larger home range contains more predators and secondly because birds that cover greater distances are easier to detect by predators. We conclude that mother-assisted releases are promising for restocking or reintroduction programmes.
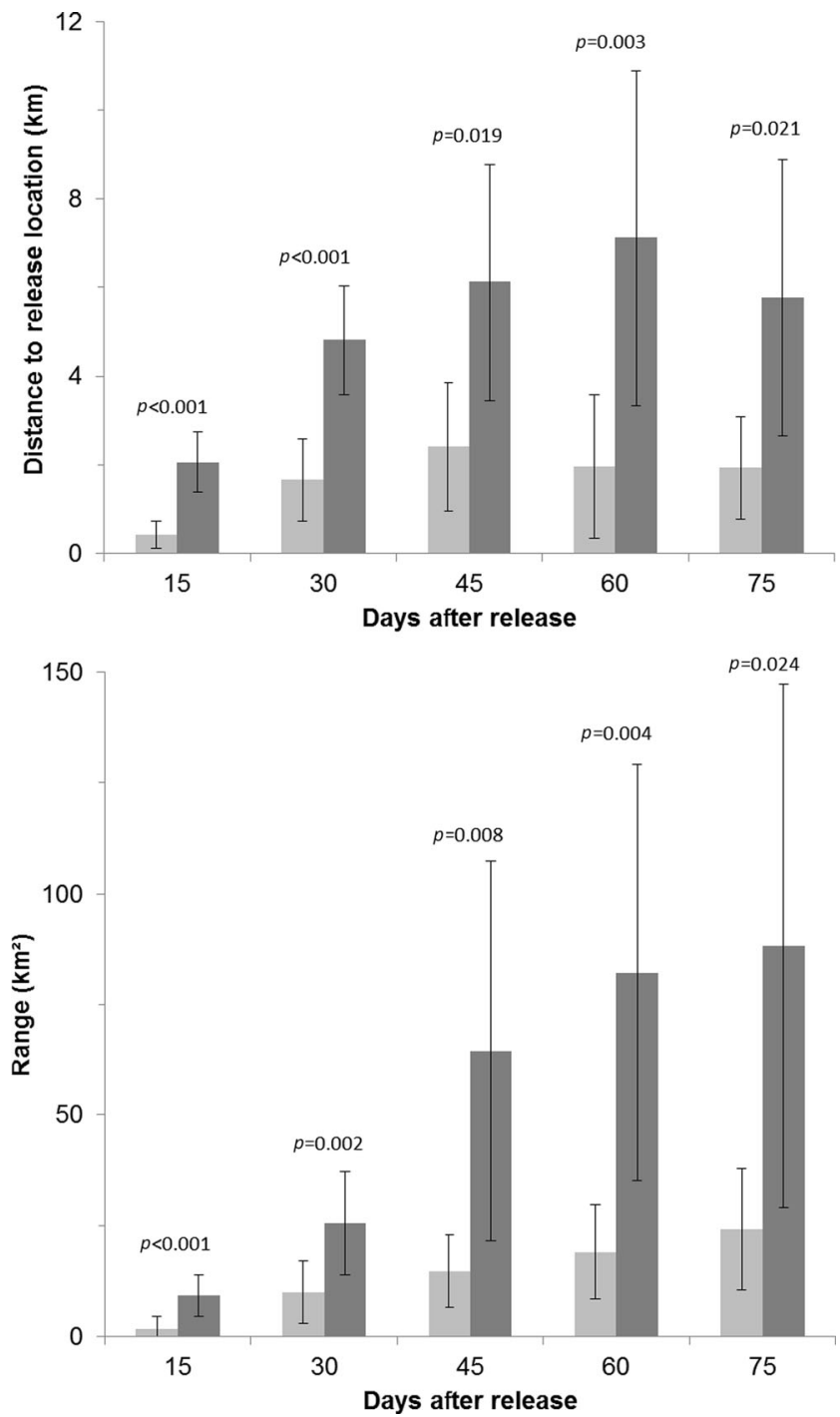

Fig. 1 Average (with $95 \%$ confidence interval) distance to release location and average cumulative range of capercaillies of the motherassisted group (light grey) and the control group (dark grey), compared by Mann-Whitney test 
Acknowledgments This study was part of a capercaillie reintroduction programme financed by the National Fund for Environmental Protection and Water Management (grant no 461/2010), Voivodeship Fund for Environmental Protection and Water Management in Wrocław (grant no 47/ 2011), the European Commission (grant LIFE11 NAT/PL/428) and the Polish State Forests.

Open Access This article is distributed under the terms of the Creative Commons Attribution License which permits any use, distribution, and reproduction in any medium, provided the original author(s) and the source are credited.

\section{References}

Heisey DM, Fuller TK (1985) Evaluation of survival and cause-specific mortality rates using telemetry data. J Wildl Manag 49:668-674
Kaplan EL, Meier P (1958) Nonparametric estimation from incomplete observations. J Am Stat Assoc 53:457-481

Krzywiński A, Keller M, Kobus A (2013) "Born to be free"-an innovatory method of restitution and protection of endangered and isolated grouse populations (Tetraonidae). Vogelwelt 134:55-64

Merta D, Kobielski J, Krzywiński A, Rzońca Z (2013) Preliminary results of the capercaillie (Tetrao urogallus) recovery program in Bory Dolnośląskie Forest, south-western Poland. Vogelwelt 134:65-74

Schroth KE (1991) Survival, movements and habitat selection of released capercaillie in the north-east Black Forest in 1984-1989. Ornis Scand 22:249-254

Siano R, Bairlein F, Exo KM, Herzog SA (2006) Survival, causes of death and spacing of captive-reared capercaillies (Tetrao urogallus L.) released in the Harz Mountains National Park. Vogelwarte 44: $145-158$

Storch I (2007) Grouse: status survey and action plan 2006-2010 IUCN. Gland, Switzerland, and Cambridge, UK, World Pheasant Association, Fordinbridge 